CHRONIC OBSTRUCTIVE PULMONARY DISEASE

\title{
Validity of spirometric testing in a general practice population of patients with chronic obstructive pulmonary disease (COPD)
}

\author{
T R Schermer, J E Jacobs, N H Chavannes, J Hartman, H T Folgering, B J Bottema, C van Weel
}

Thorax 2003;58:861-866

See end of article for authors' affiliations

Correspondence to:

T R Schermer, 229-HSV,

PO Box 9101, $6500 \mathrm{HB}$

Niimegen, The

Netherlands; t.schermer@

hag.umen.nl

Received

24 December 2002

Accepted for publication

18 June 2003
Objective: To investigate the validity of spirometric tests performed in general practice.

Method: A repeated within subject comparison of spirometric tests with a "gold standard" (spirometric tests performed in a pulmonary function laboratoryl was performed in 388 subjects with chronic obstructive pulmonary disease (COPD) from 61 general practices and four laboratories. General practitioners and practice assistants undertook a spirometry training programme. Within subject differences in forced expiratory volume in 1 second and forced vital capacity ( $\Delta \mathrm{FEV} \mathrm{V}_{1}$ and $\Delta \mathrm{FVC}$ ) between laboratory and general practice tests were measured (practice minus laboratory value). The proportion of tests with $\mathrm{FEV}_{1}$ reproducibility $<5 \%$ or $<200 \mathrm{ml}$ served as a quality marker.

Results: Mean $\Delta \mathrm{FEV}_{1}$ was 0.069 I (95\% $\mathrm{Cl}_{0.054}$ to 0.084$)$ and $\Delta \mathrm{FVC} 0.081$ I (95\% $\mathrm{Cl} 0.053$ to 0.109$)$ in the first year evaluation, indicating consistently higher values for general practice measurements. Second year results were similar. Laboratory and general practice $\mathrm{FEV}_{1}$ values differed by up to $0.5 \mathrm{I}, \mathrm{FVC}$ values by up to $1.0 \mathrm{I}$. The proportion of non-reproducible tests was $16 \%$ for laboratory tests and $18 \%$ for general practice tests $(p=0.302)$ in the first year, and $18 \%$ for both in the second year evaluation $(p=1.000)$. Conclusions: Relevant spirometric indices measured by trained general practice staff were marginally but statistically significantly higher than those measured in pulmonary function laboratories. Because of the limited agreement between laboratory and general practice values, use of these measurements interchangeably should probably be avoided. With sufficient training of practice staff the current practice of performing spirometric tests in the primary care setting seems justifiable. l: $\mathrm{n}$ recent years the use of spirometric tests has rapidly increased in primary health care. Practice guidelines assign a central role to spirometry in the management of patients with chronic obstructive pulmonary disease (COPD). ${ }^{12}$ As most of these patients are detected and treated in primary care, these guidelines are particularly relevant for general practice. $^{34}$ There is some evidence that application of spirometric testing in general practice may reduce the number of undetected cases with chronic respiratory morbidity $^{5}$ as well as diagnostic misclassification, ${ }^{6-8}$ which may lead to overall improved respiratory health. ${ }^{7}$

The validity (or "reliability") of spirometric tests is a prerequisite for their use as an instrument for diagnosis, monitoring, and management of respiratory disease. ${ }^{9}$ Despite their widespread use, little is known about the validity of spirometric tests in the primary care setting. It has been reported that at least one third of tests performed in general practice do not meet the quality criteria which apply to pulmonary function laboratories. ${ }^{10}$ Training of practitioners and nurses seems to enhance the quality of testing only temporarily. ${ }^{10}$ Four studies have shown that spirometric indices obtained in general practices may be considerably lower than those obtained in laboratories, suggesting insufficient test validity in general practice. ${ }^{11-14}$ However, none of these reports has been peer reviewed and apparent methodological shortcomings justify further studies of this topic. The main objective of the current study was to assess the extent to which the results of spirometric tests performed in general practice correspond with the results of the same tests performed in a certified pulmonary function laboratory.

\section{METHODS}

Study design and participants

The study was a repeated cross sectional within subject comparison of spirometric testing in pulmonary function laboratories and general practices. Four pulmonary function laboratories (two in universities, two in general hospitals) and 61 general practices comprising 149 general practitioners (GPs) and 185 practice assistants were involved. (In Dutch general practice the practice assistant is a paramedical professional who has been trained for administrative and patient care related activities.) A priori, we considered the laboratory spirometric tests as "gold standard"15 measurements.

GPs selected subjects who met the following inclusion criteria: age 30-75 years; current or ex-smoker; diagnosis of COPD as assigned by a GP; meeting the clinical definition of COPD ("increased cough, sputum and dyspnoea on most days for a minimum of 3 months a year for at least the previous 2 years" $) ;{ }^{16}$ post-bronchodilator forced expiratory volume in l second $\left(\mathrm{FEV}_{1}\right) \mathbf{4 0 - 9 0 \%}$ of the predicted value and/or post-bronchodilator $\mathrm{FEV}_{\mathrm{l}} / \mathrm{FVC}$ (forced vital capacity) $<88 \%$ of the predicted value for men and $<89 \%$ for women. Subjects with severe co-morbidity and/or a history of asthma, allergic rhinitis, or atopic rash were excluded.

The study was approved by the medical ethics committee of the University Medical Centre Nijmegen and all subjects gave written informed consent.

\section{Spirometry training programme}

A spirometry training programme for GPs and practice assistants was developed and pretested before the study. 
Training consisted of two 2.5 hour sessions separated by an interval of 1 month. The content of the training sessions is available online on the Thorax website (www.thorax.jnl.com/ supplemental). The training programme specifically focused on elements that need improvement in general practice spirometric tests. ${ }^{10} 17$

\section{Spirometric testing}

Data collection took place from December 1998 to January 2001. General practices and laboratories were all equipped with the same electronic spirometer (Microloop II; Micro Medical Ltd, Rochester, UK) and spirometry software (Spirare; Diagnostica Ltd, Oslo, Norway). Durability of the Microloop turbine flow sensor has proved to be acceptable. ${ }^{18}$ The spirometry software displays real time flow-volume curves, patient instructions, and a time indicator to monitor duration of expiratory and inspiratory flow but does not contain "built in" quality assurance prompts. ${ }^{4}$

In each study subject a pair of spirometric tests was performed. The first test always took place in one of the laboratories, the second in the subject's general practice. Subjects with an interval of $>30$ days between the two tests were excluded from the analysis. In case of a recent exacerbation the measurement schedule was postponed until at least 6 weeks after clinical recovery. The test sequence was repeated one year later in the same subjects.

During laboratory and general practice visits subjects performed a full (pre-bronchodilator and post-bronchodilator) spirometric test. Subjects were instructed to abstain from short acting bronchodilators for 8 hours and long acting bronchodilators for 12 hours before testing. Post-bronchodilator tests were performed 15 minutes after administration of $400 \mu \mathrm{g}$ aerosolised salbutamol by spacer. For each test at least three acceptable forced expiratory manoeuvres were required. ${ }^{9}$ The spirometric indices (including $\mathrm{FEV}_{1}$ and FVC) of the manoeuvre with the highest sum of $\mathrm{FEV}_{1}+\mathrm{FVC}$ were stored and used for analysis. Spirometers were checked for errors in readings by a research nurse every 3 months using a 3 litre syringe and "biological control" - that is, a manoeuvre performed by the research nurse herself. In cases with a deviation of $\geqslant 3 \%$ in the volume reading or a divergent outcome of the biological control manoeuvre the spirometer was replaced.

\section{Outcomes and statistical analyses}

The primary outcomes were the within subject differences between laboratory and general practice spirometric tests in terms of $\mathrm{FEV}_{1}$ and FVC $\left(\triangle \mathrm{FEV}_{1}\right.$ and $\triangle \mathrm{FVC}$, respectively). Crude mean $\triangle \mathrm{FEV}_{1}$ and $\triangle \mathrm{FVC}$ were calculated by subtracting a subject's laboratory value from the general practice value. Mean values for the primary outcomes with 95\% confidence intervals (95\% CIs) were calculated and difference versus mean plots and accompanying limits of agreement produced to express the variability between laboratory and general practice measurements. ${ }^{19} 5 \%$ trimmed means (arithmetic mean without the largest 5\% and the smallest 5\% of observations) were also calculated to rule out the impact of outliers. Adjusted mean estimates were calculated to control for potential bias in the primary outcomes due to differential timing of laboratory and general practice tests. This was done by defining three subgroups based on the circadian ("diurnal") variation of lung function $^{20}$ : (1) a potential advantage of $\geqslant 50 \mathrm{ml}$ due to time of measurement favouring the laboratory test; (2) a potential advantage $\geqslant 50 \mathrm{ml}$ favouring the general practice test; and (3) no potential advantage for either test. (The $50 \mathrm{ml}$ cut off reflects approximately half the maximum variation of $\mathrm{FEV}_{1}$ throughout the day.) The potential advantage in $\mathrm{ml}$ for groups 1 and 2 compared with group 3 was estimated using a one way analysis of variance
(ANOVA) model. In groups 1 and 2 the actual measured values of $\mathrm{FEV}_{1}$ and FVC were corrected for the estimated values from the ANOVA model. We consider the crude estimates to be the main results.

Differences in the primary outcomes between laboratories were analysed using ANOVA, and associations between primary outcomes and the number of days elapsed between laboratory and general practice spirometric tests were analysed using Pearson correlation.

The proportion of tests with a reproducibility of $<5 \%$ and $<200 \mathrm{ml}$ (test variance) between the two highest $\mathrm{FEV}_{1}$ values from the three accepted forced manoeuvres was considered as a marker of the quality of the spirometric tests. ${ }^{10}$ Differences in the proportion of non-reproducible tests in laboratories and general practices were analysed using McNemar's test. The Statistical Analysis System (SAS, Version 6.12 for UNIX) was used for analysis.

\section{RESULTS}

\section{Characteristics of general practices}

Of the 61 general practices involved, 21 (34\%) were single handed practices, 35 (58\%) were two handed or group practices, and five $(8 \%)$ were multidisciplinary health care centres. Forty practices $(65 \%)$ already possessed a spirometer before the study was initiated. Descriptive characteristics of the general practices are shown in table 1. Attendance rates in the spirometric training programme were $57 \%$ for GPs and $78 \%$ for practice assistants. In two practices GPs performed the spirometric tests, while in the remaining 59 practices the practice assistants undertook the testing.

\section{Study subjects and primary outcomes}

Matched pairs of laboratory and general practice spirometric tests were available for 388 subjects in the first year and 332

Table 1 Baseline characteristics of general practices and study subjects

\begin{tabular}{|c|c|}
\hline \multicolumn{2}{|l|}{ General practices $(n=61)$} \\
\hline No of GPs & $2.5(1.4)$ \\
\hline $\mathrm{GPs}^{\prime}$ professional experience (years) & $14.3(8.2)$ \\
\hline No of practice assistants & $3.1(1.4)$ \\
\hline Practice assistants' professional experience (years) & $10.7(7.4)$ \\
\hline Practice population size (no of patients per GP) & $1862(771)$ \\
\hline Time since introduction of spirometry (years) & $4.3(2.9)$ \\
\hline No of spirometers present & $1.8(1.2)$ \\
\hline \multicolumn{2}{|l|}{ Study subjects $(n=388)$} \\
\hline Male/female & $266 / 122$ \\
\hline Age (years) & $59.6(9.7)$ \\
\hline Current smokers, $\mathrm{n}(\%)$ & $228(59)$ \\
\hline Cumulative cigarette smoke exposure (pack years) & $28(17)$ \\
\hline Use of inhaled corticosteroids, $\mathrm{n}(\%)$ & 58 (15) \\
\hline Use of bronchodilator, $\mathrm{n}(\%)$ & $285(73)$ \\
\hline \multicolumn{2}{|l|}{$\mathrm{FEV}_{1}^{*}$} \\
\hline Pre-bronchodilator (I) & $1.80(0.66)$ \\
\hline$\%$ predicted & $60.3(18.2)$ \\
\hline Post-bronchodilator (I) & $2.00(0.66)$ \\
\hline$\%$ predicted & $66.7(17.4)$ \\
\hline \multicolumn{2}{|l|}{ FVC $^{*}$} \\
\hline Pre-bronchodilator (I) & $2.91(0.92)$ \\
\hline$\%$ predicted & $78.2(18.7)$ \\
\hline Post-bronchodilator (I) & $3.21(0.94)$ \\
\hline$\%$ predicted & $85.9(18.0)$ \\
\hline \multicolumn{2}{|l|}{$\mathrm{FEV}_{1} / \mathrm{FVC}^{*}$} \\
\hline Pre-bronchodilator (\%) & $61.9(11.7)$ \\
\hline$\%$ predicted & $80.5(14.8)$ \\
\hline Post-bronchodilator (\%) & $62.6(11.6)$ \\
\hline$\%$ predicted & $81.3(14.8)$ \\
\hline Reversibility of $\mathrm{FEV}_{1}(\%) \dagger$ & $6.8(6.2)$ \\
\hline \multicolumn{2}{|c|}{$\begin{array}{l}\text { Values are mean (SD) unless stated otherwise. } \\
\text { *Based on first year spirometric tests performed in the pulmonary function } \\
\text { laboratories. } \\
\text { †Post-bronchodilator } \mathrm{FEV}_{1} \% \text { predicted minus pre-bronchodilator } \mathrm{FEV}_{1} \% \\
\text { predicted. }\end{array}$} \\
\hline
\end{tabular}


Table 2 Mean $(95 \% \mathrm{Cl})$ and trimmed mean for crude and adjusted estimates of the primary outcomes

\begin{tabular}{|c|c|c|c|c|c|c|c|c|}
\hline & \multicolumn{4}{|l|}{ First year $(n=388)$} & \multicolumn{4}{|c|}{ Second year $(n=335)$} \\
\hline & \multicolumn{2}{|l|}{ Crude estimate } & \multicolumn{2}{|l|}{ Adjusted* estimate } & \multicolumn{2}{|l|}{ Crude estimate } & \multicolumn{2}{|l|}{ Adjusted ${ }^{*}$ estimate } \\
\hline & Mean & $\begin{array}{l}\text { Trimmed } t \\
\text { mean }\end{array}$ & Mean & $\begin{array}{l}\text { Trimmed } t \\
\text { mean }\end{array}$ & Mean & $\begin{array}{l}\text { Trimmed } t \\
\text { mean }\end{array}$ & Mean & Trimmed $†$ mean \\
\hline $\begin{array}{l}\Delta \mathrm{FEV}_{1} \text { (I) } \\
\text { Pre-bronchodilator }\end{array}$ & 0.079 & 0.077 & 0.085 & 0.083 & 0.065 & 0.061 & 0.072 & 0.068 \\
\hline Post-bronchodilator & $\begin{array}{l}0.058 \\
(0.039 \text { to } 0.078)\end{array}$ & 0.060 & $\begin{array}{l}0.065 \\
(0.045 \text { to } 0.085)\end{array}$ & 0.067 & $\begin{array}{l}0.050 \\
(0.029 \text { to } 0.071)\end{array}$ & 0.044 & $\begin{array}{l}0.057 \\
(0.036 \text { to } 0.079)\end{array}$ & 0.051 \\
\hline $\begin{array}{l}\text { Pooled } \neq \\
\Delta \text { FVC (I) }\end{array}$ & $\begin{array}{l}0.069 \\
(0.054 \text { to } 0.084)\end{array}$ & 0.069 & $\begin{array}{l}0.076 \\
(0.061 \text { to } 0.091)\end{array}$ & 0.075 & $\begin{array}{l}0.058 \\
(0.043 \text { to } 0.073)\end{array}$ & 0.053 & $\begin{array}{l}0.065 \\
(0.050 \text { to } 0.080)\end{array}$ & 0.060 \\
\hline Pre-bronchodilator & $\begin{array}{l}0.103 \\
(0.062 \text { to } 0.143)\end{array}$ & 0.102 & $\begin{array}{l}0.104 \\
(0.064 \text { to } 0.144)\end{array}$ & 0.104 & $\begin{array}{l}0.091 \\
(0.049 \text { to } 0.133)\end{array}$ & 0.073 & $\begin{array}{l}0.096 \\
(0.054 \text { to } 0.138)\end{array}$ & 0.078 \\
\hline Post-bronchodilator & $\begin{array}{l}0.056 \\
(0.017 \text { to } 0.095)\end{array}$ & 0.062 & $\begin{array}{l}0.061 \\
(0.022 \text { to } 0.100)\end{array}$ & 0.068 & $\begin{array}{l}0.068 \\
(0.028 \text { to } 0.107)\end{array}$ & 0.053 & $\begin{array}{l}0.074 \\
(0.035 \text { to } 0.113)\end{array}$ & 0.059 \\
\hline Pooled $\ddagger$ & $\begin{array}{l}0.081 \\
(0.053 \text { to } 0.109)\end{array}$ & 0.083 & $\begin{array}{l}0.084 \\
\text { (0.056 to } 0.112 \text { ) }\end{array}$ & 0.086 & $\begin{array}{l}0.079 \\
(0.051 \text { to } 0.108)\end{array}$ & 0.063 & $\begin{array}{l}0.085 \\
(0.056 \text { to } 0.114)\end{array}$ & 0.069 \\
\hline
\end{tabular}

A minus sign indicates higher mean laboratory values, absence of a minus sign indicates higher general practice values.

*Adjusted for the influence of differential timing between measurements performed in pulmonary function laboratory and general practice.

†Arithmetic mean calculated with exclusion of the largest $5 \%$ and the smallest $5 \%$ of the values.

$\ddagger$ Combined results of pre-bronchodilator and post-bronchodilator values.

subjects in the second year evaluation (table 1). The mean (SD) number of days between laboratory and general practice tests was 7.2 (7.8) for the first year evaluation and $11.2(8.1)$ for the second year evaluation. There was no significant correlation between the number of days between measurements and the primary outcomes $\left(\Delta \mathrm{FEV}_{1}: r=0.11 ; \Delta \mathrm{FVC}\right.$ : $r=0.13)$. In $24 \%$ of the spirometric test pairs the laboratory test was favoured by the circadian variation, in $21 \%$ of the tests the general practice test was favoured, and in 55\% neither test was favoured.

Adjusted estimates of the primary outcomes were consistently (but only marginally) higher than crude estimates (table 2). First year and second year mean $\Delta \mathrm{FEV}_{1}$ and $\triangle \mathrm{FVC}$ values were all higher for the general practice measurements. These findings were consistent for each of the laboratories involved (table 3 ). The scatter of the $\triangle \mathrm{FEV}_{1}$ and $\triangle \mathrm{FVC}$ values did not vary in a systematic way over the range of measurements (fig 1 and 2). The interval between the limits of agreements was wide in both study years for $\Delta \mathrm{FEV}_{1}$ as well as for $\triangle \mathrm{FVC}$, which indicates considerable discrepancies between the two measurements.

\section{Quality of spirometric test performance}

Because of occasional imperfections in the data transfer between the spirometer and spirometric software, information on the number of forced manoeuvres performed and $\mathrm{FEV}_{1}$ reproducibility was missing for $12(<1 \%)$ laboratory and $89(3 \%)$ general practice tests. Within the set of tests with complete information there were no tests with fewer than two forced manoeuvres in either the laboratories or practices. Table 4 shows that the proportion of nonreproducible tests-that is, $\mathrm{FEV}_{1}$ reproducibility $\geqslant 5 \%$ or $>200 \mathrm{ml}$-in the first year evaluation was $16 \%$ for the laboratories and $18 \%$ for the general practices $(p=0.302)$. The corresponding figures for the second year were $18 \%$ and $18 \%$, respectively $(\mathrm{p}=1.000)$. The proportion of non-reproducible tests in the general practices ranged from $4 \%$ in the best to $35 \%$ in the worst performing practice for the pooled first and second year data. For the four pulmonary function laboratories the corresponding range was $13-20 \%$.

\section{DISCUSSION}

The results of the current study indicate that, on average, the validity and quality of spirometric tests in Dutch general practices is satisfactory in comparison with the "gold standard" procedure, a spirometric test performed in a pulmonary function laboratory. We observed mean differences in the primary outcomes consistently in favour of general practice spirometric testing in the first as well as the second year evaluation. The overall proportion of nonreproducible spirometric tests was similar for laboratories and general practices. However, the agreement between laboratory and general practice measurements seems limited. This means that using laboratory and general practice

Table 3 Mean (SD) crude estimates of the primary outcomes by pulmonary function laboratory

\begin{tabular}{|c|c|c|c|c|}
\hline & $\begin{array}{l}\text { Laboratory } 1 \\
(n=218)\end{array}$ & $\begin{array}{l}\text { Laboratory } 2 \\
(n=131)\end{array}$ & $\begin{array}{l}\text { Laboratory } 3 / 4 \dagger \\
(n=39)\end{array}$ & $p$ valuef \\
\hline \multicolumn{5}{|l|}{ First year } \\
\hline$\Delta \mathrm{FEV}_{1}{ }^{*}(\mathrm{l})$ & $0.078(0.20)$ & $0.053(0.21)$ & $0.078(0.22)$ & 0.286 \\
\hline \multirow{2}{*}{\multicolumn{5}{|c|}{ Second year }} \\
\hline & & & & \\
\hline $\begin{array}{l}\Delta \mathrm{FEV}_{1}{ }^{*}(\mathrm{l}) \\
\Delta \mathrm{FVC}^{*}(\mathrm{l})\end{array}$ & $\begin{array}{l}0.082(0.21) \\
0.086(0.36)\end{array}$ & $\begin{array}{l}0.016(0.19) \\
0.095(0.42)\end{array}$ & $\begin{array}{l}0.036(0.13) \\
-0.016(0.25)\end{array}$ & $\begin{array}{l}<0.001 \\
0.115\end{array}$ \\
\hline
\end{tabular}

A minus sign indicates higher mean laboratory values, absence of a minus sign indicates higher general practice values.

*Combined results of pre-bronchodilator and post-bronchodilator values

+Because of the small number of study subjects $(n=7)$ the results of laboratory 4 have been added to the results of laboratory 3, the laboratory with the next smallest number of subjects.

†ANOVA test for difference between laboratories. 

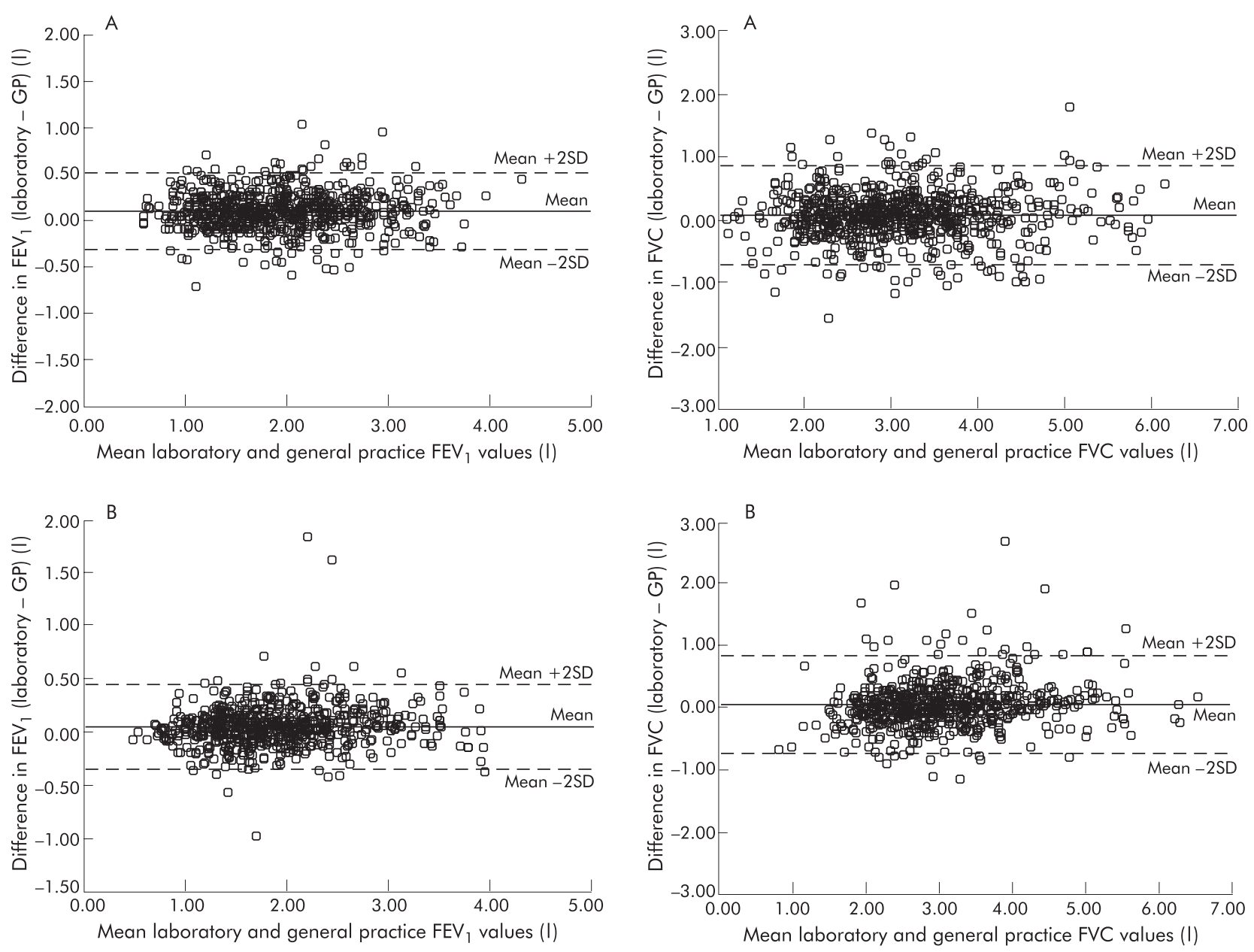

Figure 1 Difference in forced expiratory volume in 1 second $\left(\mathrm{FEV}_{1}\right)$ against mean plots for $(A)$ the first year $(n=730)$ and $(B)$ the second year $(n=656)$ evaluation. Pre-bronchodilator and post-bronchodilator values are pooled. The dashed horizontal lines indicate the limits of agreement. ${ }^{19}$

Figure 2 Difference in forced vital capacity (FVC) against mean plots for $(A)$ the first year $(n=730)$ and $(B)$ the second year $(n=656)$ evaluation. Pre-bronchodilator and post-bronchodilator values are pooled. The dashed horizontal lines indicate the limits of agreement. ${ }^{19}$

measurements interchangeably should probably be avoided in practice.

\section{Strengths and limitations of the study}

We aimed to compare, as strictly as possible, the spirometric performance of general practice and laboratory staffs. Performance depends on a number of factors related to the executor of the test-quality of subject instruction, intensity of coaching during forced manoeuvres, critical assessment of acceptability of separate manoeuvres, and test reproducibility. ${ }^{21}$ As we wished to minimise any potential bias in the comparison, we chose to equip practices and laboratories with the same type of spirometer and to check spirometer readings at the same 3 monthly intervals at both locations. Although portable turbine spirometers like the one used in our study cannot easily be calibrated on the spot and are not commonly used in laboratories, we believe that ruling out the "equipment factor" makes the comparison fairer, as turbine spirometers may produce $\mathrm{FEV}_{1}$ and FVC values which diverge from the advanced equipment normally used in laboratories. $^{22}$

From a methodological point of view, randomisation of the order in which laboratory and general practice tests took place would have been the preferred approach. However, because most of our study subjects $(67 \%)$ were participating in an ongoing randomised controlled clinical trial, ${ }^{23}$ the order of the tests was dictated by the trial protocol. We cannot

therefore rule out the possibility of a systematic "one sided" bias in favour of either general practice or laboratory spirometric testing due to natural variability in lung function. Sources of short term intra-individual variability such as airway reactivity ${ }^{21}$ and diurnal variation in lung function ${ }^{20}$ may have influenced our findings. Although we used a rather approximate method to adjust for the latter variable, this factor did not seem to bias the results significantly. We consider it implausible that other intra-individual factors may have systematically put the laboratory tests at a disadvantage.

Although we cannot rule out a possible "learning effect" in study subjects due to repetition of spirometric testing within a short time span, ${ }^{24}$ we believe that the order of tests alone cannot fully explain our results. Three arguments support this view: (1) Most subjects had been diagnosed as having COPD several years earlier, which makes it quite likely that most of them already had a "history" of spirometric testing before entering the study, especially since most practices had been using spirometric tests for some time. (2) All subjects performed a full spirometric test in their general practice several weeks before the first visit to the laboratory to assess study eligibility. In other words, they could not be entirely "naive" with regard to spirometric testing before the tests for the actual evaluation study were performed. (3) The differences in favour of general practice spirometric testing persisted after a year of regular monitoring of lung function. 
Table 4 Differences between general practices and pulmonary function laboratories in reproducibility in $\mathrm{FEV}_{1}$ in spirometric tests for the first year data $(n=693)^{*}$

\begin{tabular}{|c|c|c|c|}
\hline \multirow[b]{2}{*}{ General practice } & \multicolumn{2}{|c|}{ Pulmonary function laboratory } & \\
\hline & $\begin{array}{l}\mathrm{FEV}_{1} \text { reproducibility } \\
<5 \% \text { and }<200 \mathrm{ml}\end{array}$ & $\begin{array}{l}\mathrm{FEV}_{1} \text { reproducibility } \\
\geqslant 5 \% \text { and } \geqslant 200 \mathrm{ml}\end{array}$ & \\
\hline \multirow{3}{*}{$\begin{array}{l}\mathrm{FEV} \text { reproducibility } \\
<5 \% \text { and }<200 \mathrm{ml} \\
\mathrm{FEV} \text { reproducibility } \\
\geqslant 5 \% \text { and } \geqslant 200 \mathrm{ml}\end{array}$} & $484(70) \dagger$ & $85(12)$ & $569(82)$ \\
\hline & $99(14)$ & $25(4) \dagger$ & $124(18)$ \\
\hline & $583(84)$ & $110(16)$ & \\
\hline
\end{tabular}

Values are numbers (\%) of tests.

*Pre-bronchodilator and post-bronchodilator tests are pooled.

†Concordance between laboratory and general practice test reproducibility within the same subject.

Individual learning curves in study subjects should have levelled off by that time. ${ }^{24}$ Another explanation for the observed higher general practice values may be the performance level of the laboratory technicians. It has previously been recognised that significant variation may exist between laboratories. ${ }^{25}$ This could mean that, at least in some cases, we actually used a "gilded standard" instead of a pure "gold standard".

In spirometry a widely used criterion for unacceptable performance is fewer than two acceptable manoeuvres. ${ }^{9}$ Unfortunately we were not able to perform a full evaluation of all acceptability markers-that is, adequacy of the start of the forced expiration, duration of the expiration, abrupt ending or cough during the manoeuvre ${ }^{9}$ - because the Spirare spirometry software used only stores one "best" manoeuvre. A study performed in primary care practices in New Zealand looked into quality assurance data and found that only a third of spirometric tests performed by trained practitioners and nurses fulfilled the minimum quality criterion of two or more acceptable manoeuvres. ${ }^{10}$ Although in the current study we could not evaluate all separate manoeuvres, we have previously observed that manoeuvres performed by a sample of trained practice assistants are mostly judged to be acceptable by experienced lung function technicians. ${ }^{26}$ Apart from the relatively small proportion of tests with missing data, we can be sure that at least two manoeuvres were obtained in all other spirometric tests. Reproducibility of $\mathrm{FEV}_{1}$ cannot be calculated on the basis of a single $\mathrm{FEV}_{1}$ value.

\section{Comparison with previous studies}

Our findings contradict previous reports on the validity of general practice spirometric testing. ${ }^{1-14}$ These studies consistently reported lower mean $\mathrm{FEV}_{1}$ and FVC values for general practice spirometric tests with differences of 70$280 \mathrm{ml}$ for $\mathrm{FEV}_{1}{ }^{11}{ }^{14}$ and $360 \mathrm{ml}$ for FVC. ${ }^{11}$ The presence or absence of factors responsible for short term intra-individual lung function variability, as discussed above, may explain the discrepancy between the studies, as may the diverging study populations involved (asthmatics, ${ }^{11}$ subjects with respiratory symptoms, ${ }^{13}$ adult patients with limited airflow, ${ }^{14}$ those with severe COPD, ${ }^{12}$ and a heterogeneous group of patients with COPD in our study).

There are several reasons why we believe that our study reflects the actual validity of general practice spirometric testing. Firstly, our training programme was probably more elaborate than those in other studies because we specifically emphasised elements of test performance which are now known often to be insufficient in general practice. ${ }^{10}{ }^{17}$ This tailored programme may have prepared practice assistants and GPs better for their task. Also, as far as can be extracted from the published reports, other studies did not use spirometers which display flow-volume curves. We have previously reported that real time feedback of information from flow-volume curves may lead to improved performance in spirometric testing. ${ }^{26} \mathrm{~A}$ final alternative explanation may be that in our study, unlike in some of the earlier studies, ${ }^{11}{ }^{14}$ most of the spirometric tests were performed by practice assistants instead of practitioners. As practice assistants will generally have more time available, they might take more time to attain a satisfactory test result. In our view, similar results could be achieved in other countries or healthcare settings as long as training of the professionals who perform the spirometric tests is of sufficient quality and intensity.

\section{Conclusions}

We conclude that spirometric indices relevant for the management of COPD obtained in trained general practices were marginally but statistically significant higher than those measured in certified pulmonary function laboratories. The quality of spirometric tests in laboratories and general practices in terms of test reproducibility seemed equivalent. However, as the agreement between spirometric tests performed in the laboratory and in general practice was limited, using these measurements interchangeably should probably be avoided in practice. The results of this study seem to support the already widespread practice of performing spirometric tests in primary care settings. Further encouragement of primary care physicians to implement spirometric tests therefore seems justifiable, providing the training of practice staff is sufficient.

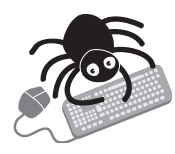

The content of the training sessions is available online on the Thorax website at www.thoraxjnl.com/ supplemental.

\section{Authors' affiliations}

T R Schermer, J E Jacobs, N H Chavannes, J Hartman, H T Folgering, B J Bottema, C van Weel, Department of General Practice, University Medical Centre Nijmegen; Centre for Quality of Care Research, University Medical Centre Nijmegen and University of Maastricht; Department of General Practice, University of Maastricht; Department of Pulmonology Dekkerswald, University Medical Centre Nijmegen, The Netherlands

\section{REFERENCES}

1 COPD Guidelines Group of the Standards of Care Committee of the BTS. BTS guidelines for the management of chronic obstructive pulmonary disease. Thorax 1997;52(Suppl 5):S1-28.

2 Pauwels RA, Buist AS, Calverley PM, et al. Global strategy for the diagnosis, management, and prevention of chronic obstructive pulmonary disease. NHLBI/WHO Global Initiative for Chronic Obstructive Lung Disease (GOLD) Workshop summary. Am J Respir Crit Care Med 2001;163:1256-76.

3 van Schayck CP, van Herwaarden CLA, Barnes PJ, et al. Recommendations based on guidelines on the management of mild to moderately severe chronic obstructive pulmonary disease: some practical applications in primary care. Asthma Gen Pract 1998;6:35-9. 
4 Ferguson GT, Enright PL, Buist AS, et al. Office spirometry for lung health assessment in adults. A consensus statement from the National Lung Health Education Program. Chest 2000;117:1146-61.

5 van den Boom G, van Schayck CP, van Molken MP, et al. Active detection of chronic obstructive pulmonary disease and asthma in the general population. Results and economic consequences of the DIMCA program. Am J Respir Crit Care Med 1998;158:1730-8.

6 Pinnock H, Carley-Smith J, Kalideen D. Spirometry in primary care: an analysis of the first 100 patients referred in one general practice. Asthma Gen Pract 1999;7:23-4.

7 Spann SJ. Impact of spirometry on the management of chronic obstructive airway disease. J Fam Pract 1983;16:271-5.

8 Griffiths C, Feder G, Wedzicha J, et al. Feasibility of spirometry and reversibility testing for the identification of patients with chronic obstructive pulmonary disease on asthma registers in general practice. Respir Med 1999;93:903-8.

9 American Thoracic Society. Standardization of spirometry: 1994 update. Am J Respir Crit Care Med 1995;152:1107-36.

10 Eaton T, Withy S, Garrett JE, et al. Spirometry in primary care practice: the importance of quality assurance and the impact of spirometry workshops. Chest 1999;116:416-23.

11 Mulder HH, van der Molen T, Postma DS, et al. Measuring FEV 1 in general practice. Eur Respir J 1996;9:121s.

12 Woolhouse I, O'Hickey SP. Accuracy of spirometry measured in general practice compared to a hospital pulmonary function laboratory. Eur Respir J 1999; 14(Suppl 30):273s.

13 den Otter JJ, de Bruyn-Schmidt M, Peters LGM, et al. Microplus, a fancy or fantastic instrument for general practice? Eur Respir J 1994:7:53s.

14 Ponsioen BP, Bohnen AM, Martha I, et al. Measurement of FEV 1 and FVC with a hand held spirometer by GPs: feasibility and validity. Primary Care Respir J 2000; 11:68-9.
15 Knottnerus JA, van Weel C, Muris JW. Evidence base of clinical diagnosis: evaluation of diagnostic procedures. BMJ 2002;324:477-80.

16 Siafakas NM, Vermeire P, Pride NB, et al. Optimal assessment and management of chronic obstructive pulmonary disease (COPD). Eur Respir J 1995;8:1398-420.

17 den Otter JJ, Knitel M, Akkermans RP, et al. Spirometry in general practice: the performance of practice assistants scored by lung function technicians. Br J Gen Pract 1997:47:41-2.

18 Dirksen A, Madsen F, Pedersen OF, et al. Long term performance of a hand held spirometer. Thorax 1996;51:973-6.

19 Bland JM, Altman DG. Statistical methods for assessing agreement between two methods of clinical measurement. Lancet 1986;i:307-10.

20 Borsboom GJ, van Pelt W, van Houwelingen HC, et al. Diurnal variation in lung function in subgroups from two Dutch populations: consequences for longitudinal analysis. Am J Respir Crit Care Med 1999;159:1 163-71.

21 Enright PL, Connett JE, Kanner RE, et al. Spirometry in the Lung Health Study: II. Determinants of short-term intraindividual variability. Am J Respir Crit Care Med 1995;151:406-11.

22 Rebuck DA, Hanania NA, D'Urzo AD, et al. The accuracy of a handheld portable spirometer. Chest 1996;109:152-7.

23 Chavannes NH, Schermer TRJ, Wouters EF, et al. Treatment of COPD in general practice: the COOPT study. Eur Respir J 2001;18(Suppl 33):348S

24 Madsen F, Ulrik CS, Dirksen A, et al. Patient-administered sequential spirometry in healthy volunteers and patients with alpha 1-antitrypsin defiency. Respir Med 1996;90:131-8.

25 Dowson $\amalg$, Mushtaq M, Watts T, et al. A re-audit of pulmonary function laboratories in the West Midlands. Respir Med 1998:92:1155-62.

26 Schermer T, Hartman J, Lauwers C, et al. Feedback information from flow volume curves to the practice assistant improves spirometry test quality in general practice. Prim Care Respir J 2001;10:4-7.

\section{LUNG ALERT}

Mite-proof impermeable covers do not improve signs and symptoms of allergic rhinitis

$\Delta$ Terreehorst I, Hak E, Oosting AJ, et al. Evaluation of impermeable covers for bedding in patients with allergic rhinitis. N Engl J Med 2003;349:237-46

$\mathrm{T}$ he importance of environmental allergen avoidance in allergic rhinitis is widely promoted although its true clinical value is unclear. This multicentre, randomised, double blind, placebo controlled trial examined the effects of house dust mite impermeable covers on symptom control in a group of Dutch patients with allergic rhinitis over a 1 year period (114 patients in treatment group, 118 in control group). Subjects were assessed on a rhinitis specific visual analogue scale, a daily symptom scale, nasal allergen provocation response, and levels of Dermatophagoides pteronyssinus (Der pl) and D farinae (Der fl) in domestic dust samples. Despite a clear reduction in the concentration of these allergens in the treatment group at 12 months $(1.29 \vee 4.84 \mu \mathrm{g} / \mathrm{g}$ dust in the control group, $\mathrm{p}<0.001$ ), the use of mite proof covers failed to improve clinical indices of allergic rhinitis in house dust mite sensitised individuals.

The negative findings in this study indicate that strategies aimed solely at reducing specific allergen exposure are of limited use in managing symptomatic allergic rhinitis. Heterogeneous patient predisposition and provocation by other environmental agents are among the reasons cited for the lack of efficacy of these devices.

F Chua

Queen Elizabeth II Hospital, Welwyn Garden City, UK f.chua@ud.ac.uk 